\title{
UNILATERAL ABSENCE OF A PULMONARY ARTERY: A RARE DISORDER WITH VARIABLE PRESENTATION
}

\author{
Sadashiva Gowda $H^{1}$
}

${ }^{1}$ Associate Professor, Department of Radiodiagnosis, Vijayanagar Institute of Medical Sciences, Bellary.

\begin{abstract}
Unilateral absence of a pulmonary artery (UAPA) is a rare condition with an estimated prevalence of 1 in 200,000 young adults. Most commonly, UAPA occurs in conjunction with cardiovascular abnormalities such as tetralogy of Fallot or cardiac septal defects, but it can also occur in an isolated manner. Patients with isolated UAPA can remain asymptomatic into late adulthood but usually report symptoms such as dyspnea or chest pain or suffer from hemoptysis or recurrent infections. Diagnosis can be difficult due to the rarity of the condition and its nonspecific presentation. We present a case of a 60 -year-old female who presented with history of chronic cough and was found to have UAPA. Typical findings on CT were discussed.
\end{abstract}

KEYWORDS: Pulmonary artery, CT.

HOW TO CITE THIS ARTICLE: Sadashiva Gowda H. "Unilateral Absence of a Pulmonary Artery: A Rare Disorder ith Variable Presentation". Journal of Evolution of Medical and Dental Sciences 2015; Vol. 4, Issue 91, November 12; Page: 15714-15716, DOI: $10.14260 /$ jemds/2015/2266.

CASE PRESENTATION: An 60yr old female presented with chronic cough.A computed tomography (CT) pulmonary angiogram showed asymmetric lung fields, with a right hemithorax that was smaller than the left. Diffuse reticular opacities with honeycombing pattern noted in right lung fields.Cross-sectional CT images demonstrated a absent right main pulmonary artery. No evidence of embolic occlusion or surgical changes was present.

DISCUSSION: UAPA is a rare condition, with an estimated prevalence of 1 in 200,000 young adults.(1) Most commonly, UAPA occurs in conjunction with cardiovascular abnormalities such as tetralogy of Fallot or cardiac septal defects, but it can also occur in an isolated manner.(1,2) Isolated UAPA involves the right lung in about two thirds of cases.(3) Due to embryologic relationships, UAPA commonly occurs on the side of the chest opposite the aortic arch.(4)

The exact embryologic cause of UAPA is a matter of debate and is likely different in left- vs. right-sided UAPA. In both cases, however, altered development of a sixth aortic arch segment is thought to result in a ductal origin to a pulmonary artery that leads to the proximal interruption of that vessel when the ductal tissue regresses at the time of birth.(4) Distal intrapulmonary branches of the affected artery usually remain intact and can be supplied by collateral vessels from bronchial, intercostal, internal mammary, subdiaphragmatic, subclavian, or even coronary arteries.(5, 6)

Patients with isolated UAPA can present in a variety of ways. A 2002 review of 108 cases of UAPA revealed a median age of presentation of 14 years. (3) The combination of chest pain, pleural effusion, and recurrent infections was present in $37 \%$ of patients, while dyspnea or exercise intolerance was present in $40 \%$ of patients.

Financial or Other, Competing Interest: None.

Submission 21-04-2015, Peer Review 22-04-2015,

Acceptance 31-10-2015, Published 12-11-2015.

Corresponding Author:

Dr. Sadashiva Gowda $H$,

Department of Radiodiagnosis,

Vijaynagar Institute of Medical Sciences,

Bellary, Karnataka.

E-mail:drsadashiv27@yahoo.com

DOI:10.14260/jemds/2015/2266.
Pulmonary hypertension was found in $44 \%$ of patients that were tested for the disorder.

Hemoptysis occurred in about $20 \%$ of patients, and high-altitude pulmonary edema was seen in approximately $10 \%$ of patients.(3) Seven deaths were noted in the case series and included mortality from massive pulmonary hemorrhage, right heart failure, respiratory failure, pulmonary hypertension, and high-altitude pulmonary edema. Only 14 of 108 patients with isolated UAPA were asymptomatic at the time of their diagnosis and throughout variable follow-up.(3)

At the time of our patient's presentation, he reported dyspnea at rest and exercise intolerance. UAPA could definitely be a cause of his dyspnea, and it should be noted that his left lung received $32 \%$ of total ventilation on his ventilation perfusion scan but no detectable perfusion, resulting in a large amount of dead space.

Pulmonary hypertension could also be a cause for the patient's dyspnea, and indeed, the patient's main pulmonary artery was enlarged, measuring $3.7 \mathrm{~cm}$ on his CT pulmonary angiogram (Figure2). However, that study showed no signs of secondary right heart strain. An echocardiogram was ordered but not performed before the patient was lost to follow-up. Other possible causes of dyspnea and exercise intolerance include obesity and deconditioning.

The etiology of recurrent infections observed in patients with UAPA is likely multifactorial. Lack of arterial blood flow to the affected lung may result in poor delivery of inflammatory cells to sites of inflammation and impair ciliary function.(5) In addition, poor blood flow to the affected lung may result in alveolar hypocapnia, leading to secondary bronchoconstriction and mucous trapping.(5) Chronic infection can lead to bronchiectasis in some patients.(5,7)

Hemoptysis is a potentially serious complication of UAPA. Hemoptysis appears to be caused by large collateral circulations that subject venous systems to unusually high pressures. While Hemoptysis can be chronic and self-limited, cases of massive hemoptysis have been reported in the literature. $(5,8,9)$ Diagnosing UAPA can be difficult, but important clues are present in chest radiographs. The chest radiograph of patients with UAPA typically shows asymmetric lung fields, with an ipsilateral small hemithorax holding a hyperlucent lung. $(1,7)$ 
The mediastinum will be shifted towards the affected side, and the hilar vasculature on that side will be absent or greatly diminished. The ipsilateral hemidiaphragm may be elevated.

Extensive transpleural collateral circulation in the apices of the lung may mimic tuberculosis by producing an appearance known as pulmonary pseudofibrosis.(1) The contralateral lung may be hyperinflated beyond the midline and appear plethoric due to increased blood flow.

When suspicious findings are noted on a chest radiograph, the diagnosis of UAPA can be definitively made by $\mathrm{CT}$, magnetic resonance imaging (MRI), or transthoracic echocardiogram. On cross-sectional imaging, the absent pulmonary artery will typically terminate within $1 \mathrm{~cm}$ of its expected origin from the main pulmonary artery.(1) Other findings that may be noted on CT or MRI include intact peripheral branches of the pulmonary artery, variable collateral circulation, mosaic parenchymal changes, and bronchiectasis secondary to recurrent infections. $(1,5,7)$

Transthoracic echocardiogram can also be used to diagnose UAPA and is advantageous because the examiner can look for coexisting cardiac malformations at the same time. Angiography is considered the gold standard for the diagnosis of UAPA but is invasive and typically unnecessary, unless it is being used as a preoperative test for a patient who has developed hemoptysis or severe infection.(7)

Ventilation perfusion scanning is not necessary for the diagnosis of UAPA, but if done will show normal or diffusely diminished Xenon-127 uptake during the wash-in and equilibrium phase, coupled with absent or greatly diminished perfusion in the affected lung.(1) Xenon washout typically shows no delay.(1) There is currently no consensus concerning treatment of patients with UAPA. Some authors have recommended using serial echocardiography to monitor asymptomatic adults for the development of pulmonary hypertension.(10)

Patients who develop pulmonary hypertension can be treated medically with vasodilator therapy.(3,11) Alternatively, revascularization of peripheral branches of the affected pulmonary artery to the pulmonary hilum can be attempted, and there are reports of successful revascularization procedures, mostly in the pediatric population. $(2,12,13)$

Hemoptysis may be treated with embolization, lobectomy, or pneumonectomy.(8,9) Embolization is a relatively safe procedure with few side effects and is a viable alternative to pneumonectomy in patients experiencing hemoptysis.(8) Severe infections may require lobectomy or pneumonectomy, and any pulmonary surgery in a patient with UAPA may be complicated by the presence of systemic collaterals. ${ }^{(5)}$

\section{REFERENCES:}

1. Bouros D, Pare P, Panagou P, Tsintiris K, Siafakas N. The varied manifestation of pulmonary artery agenesis in adulthood. Chest. 1995; 108(3):670-676. [PubMed]

2. Presbitero P, Bull C, Haworth SG, de Leval M. R. Absent or occult pulmonary artery. $\mathrm{Br}$ Heart J. 1984; 52(2):178-185. [PMC free article] [PubMed]

3. Ten Harkel A. D, Blom NA, Ottenkamp J. Isolated unilateral absence of a pulmonary artery: a case report and review of the literature. Chest. 2002; 122(4):1471-1477. [PubMed]

4. Pfefferkorn J. R, Löser H, Pech G, Toussaint R, Hilgenberg F. Absent pulmonary artery. A hint to its embryogenesis. Pediatr Cardiol. 1982; 3(4):283-286. [PubMed]

5. Kadir I S, Thekudan J, Dheodar A, Jones M T, Carroll K B. Congenital unilateral pulmonary artery agenesis and aspergilloma. Ann Thorac Surg. 2002; 74(6):2169-2171. [PubMed]

6. Bockeria L A, Makhachev O A, Khiriev T K, Abramyan M A. Congenital isolated unilateral absence of pulmonary artery and variants of collateral blood supply of the ipsilateral lung. Interact Cardiovasc Thorac Surg. 2011; 12(3):509-510. [PubMed]

7. Griffin N, Mansfield L, Redmond KC, Dusmet M, Goldstraw P, Mittal T K, Padley S. Imaging features of isolated unilateral pulmonary artery agenesis presenting in adulthood: a review of four cases. Clin Radiol. 2007; 62(3):238-244. [PubMed]

8. Reñé M, Sans J, Dominguez J, Sancho C, Valldeperas J. Unilateral pulmonary artery agenesis presenting with hemoptysis: treatment by embolization of systemic collaterals. Cardiovasc Intervent Radiol. 1995; 18(4):251-254. [PubMed]

9. Bekoe S, Pellegrini R V, DiMarco R F, Jr, Grant K J, Woelfel GF. Pneumonectomy for unremitting hemoptysis in unilateral absence of pulmonary artery. Ann Thorac Surg. 1993; 55(6):1553-1554. [PubMed]

10. Turner D R, Vincent J A, Epstein ML. Isolated right pulmonary artery discontinuity. Images Paediatr Cardiol. 2000; 4:24-30. [PMC free article] [PubMed]

11. Shostak E, Sarwar A. A 50-year-old woman with dyspnea, lower extremity edema, and volume loss of the right hemithorax. Chest. 2009; 136(2):628-632. [PubMed]

12. Welch K, Hanley F, Johnston T, Cailes C, Shah MJ. Isolated unilateral absence of right proximal pulmonary artery: surgical repair and follow-up. Ann Thorac Surg. 2005; 79(4):1399-1402. [PubMed]

13. Toews WH, Pappas G. Surgical management of absent right pulmonary artery with associated pulmonary hypertension. Chest. 1983; 84(4):497-499. [PubMed] 


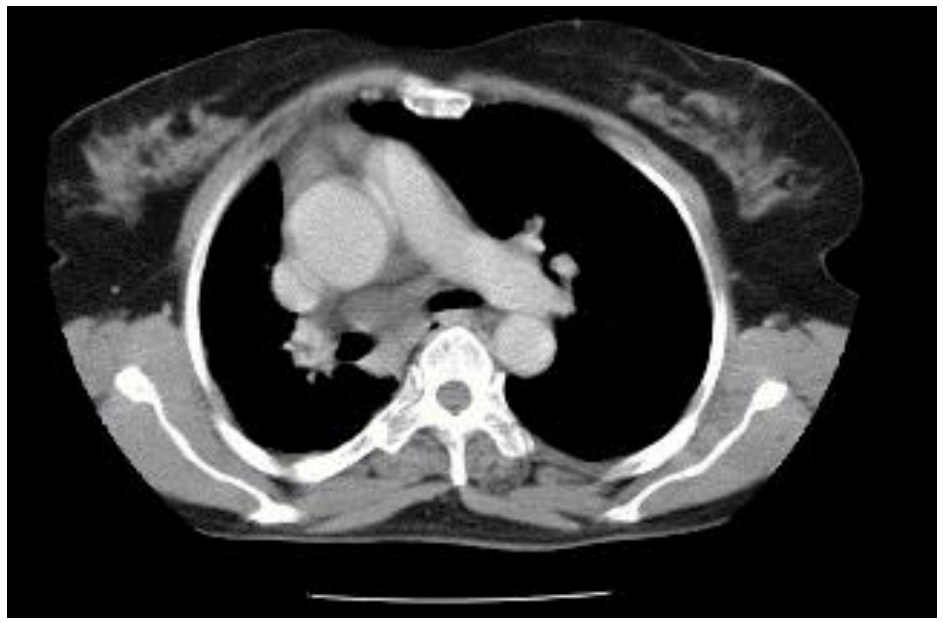

Fig. 1: CECT Chest shows absent right main pulmonary artery

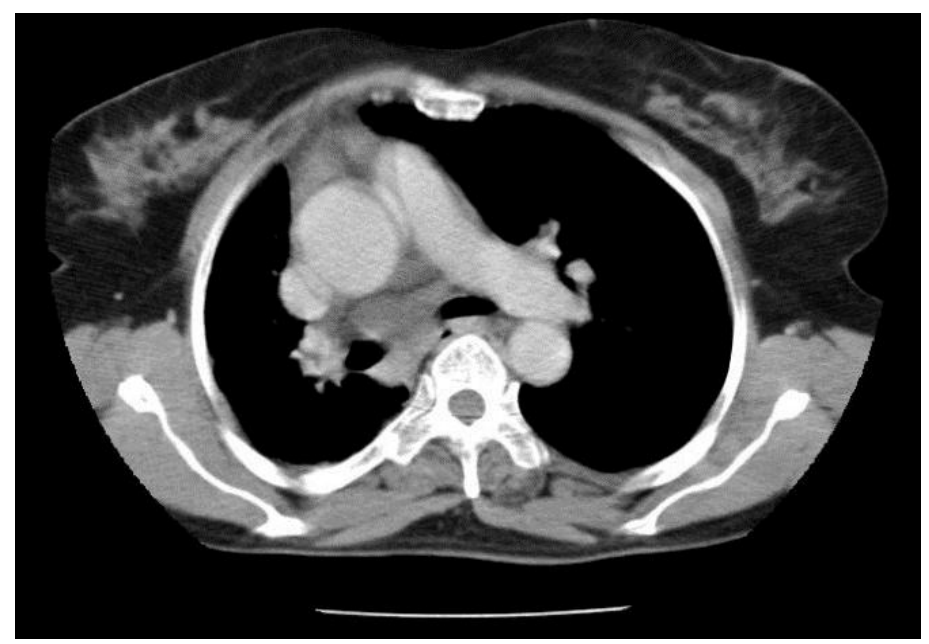

Fig. 2: CT shows decreased right hemithorax with absent right pulmonary artery 